effectiveness of any organization depends ultimately on the men who use it. A rigid system of organization may easily defeat its own object and hinder scientific and technical advance; whereas with flexibility and clear mutual understanding on the part of the Minister and official or administrator, the scientist and the technologist, it may well be possible to achieve the wisest and most effective deployment of resources in materials and man-power with much less strain on Ministers and a minimum of formal organization. It is to be hoped that the examination the Prime Minister is now conducting will pay particular attention to the Lord President's office and its staffing, and to this whole question of the organization of the scientific and technical effort of Britain, in relation to the communication of scientific and technical knowledge and advice, its continuous acquisition and the training and deployment of scientific and technical man-power. The results of that section at least of his inquiry should be made available for informed discussion; meanwhile, the Parliamentary and Scientific Committee and some of the learned and professional societies associated with it could well examine some of the issues which were brought to light in the debates on the Department of Scientific and Industrial Research Bill, the importance of which has been emphasized since in connexion with nuclear energy and other matters.

\section{THE HISTORY OF THE MICROSCOPE}

Microscopium

By Maria Rooseboom. Pp. 60. (Communication No. 95 from the National Museum for the History of Science, Leiden, Holland.) (Leiden: National Museum for the History of Science, 1956.) n.p.

THIS is, in effect, a brief history of the chief development of the optical microscope, from Robert Hooke and Leeuwenhoek to the phase-contrast instrument for which Prof. Zernike received the Nobel Prize in 1953. It is particularly notable for the superb full-page illustrations, of which a number are in colour. As the size of the page is roughly 12 in. $\times 8$ in. and the reproduction excellent they repay careful study. The instruments represented are mostly in the Dutch National Museum for the History of Science at Leyden and it is flattering to our national pride that so many of them should be of English origin, as is also the fact that the book appears in English and is adorned with well-chosen quotations from early English writers.

These quotations give rise to a little riddle. The book begins and ends with an extract from a poem "In Commendation of the Microscope" by Henry Power, dated 1661. Now the only printed book by Henry Power is his "Experimental Philosophy in Three Books", 1664, the first book of which deals with microscopical observations, but does not contain the poem, which, so far as I know, existed only in the Sloane MS. at the beginning of this century, although it may have been printed since. The author gives no indication of the source of the poem, but shows the extracts in what would appear to be facsimile reproduction of seventeenth-century printing. I suspect an amiable mystification. Again, if it is not ungracious to raise trifling eriticism of what is in so many ways a delightful book, the text is introduced by an English passage, in quotation marks, followed by "With these words Pierre Borel ....". But Borel's book was in Latin. The serious student, whom there is so much to please in this work, would have appreciated references, which are everywhere lacking, to indicate the sources of the various interesting and apposite citations.

The text is in the nature of illuminating notes concerning the development of various parts and functions of the microscope. For example, one section deals with the evolution of the modern apochromatic objective from the little-known achromatic design of Beeldsnijder, of about 1791, to modern times, illustrated with excellent pictorial diagrams; another section deals with methods of illumination, often neglected; other sections with focusing and with the movement of the stage. One interesting page shows, in silhouette, the pattern of selected typical microscopes from 1800 to 1900. The binocular microscope, from Cherubin d'Orleans to Zeiss-Winkel of 1954, also has its couple of informative pages, with a colour plate of the $R$. and $J$. Beck instrument of 1875 .

To be effective, a brief survey of this kind demands wide knowledge, good taste, fine drawing, excellent technique of reproduction and considerable financial support. The National Museum for the History of Science at Leyden is to be congratulated that all these have been forthcoming to help in the production of the elegant record before us.

\section{E. N. DA C. ANDrade}

\section{TECHNICAL APPLICATIONS OF RADIOACTIVITY}

Die Technischen Anwendungen der Radioaktivität Von Dr. Engelbert Broda und Dr. Thomas Schönfeld. Pp. $x+313$. (Berlin : Veb Verlag Technik; München : Porta-Verlag, 1956.) 19 D.M.

$\mathrm{B}^{\mathrm{T}}$ RODA AND SCHÖNFELD have written a most valuable book. It is the first of its kind in which the technical applications of radioactivity are complete with many hundreds of references, and the discussion of the whole subject is done extremely well. There are thirteen main chapters. After the introduction comes a very well-written chapter on the fundamentals of radioactivity which includes discussions on such subjects as ions, molecules, isotopes, fission, radiations and their absorption and radiochemical equilibrium. The third chapter deals with the measurements of radioactivity, giving a very concise picture of counting techniques. The next chapter deals with the production and chemical purification of radioisotopes. This chapter is very short but gives in ten pages all the relevant facts. Chapter 5 deals with isotopes used as indicators and gives details of the rare occasions where the emanation method can be used.

The next six chapters form the main part of the book (comprising 220 pages) and deal with the application of radioactivity or the radiation of radioisotopes in different fields. This is extremely well organized according to subjects and should be of equal interest to the chemist or to any scientist working in a research laboratory, irrespective of the subject he is dealing with. 